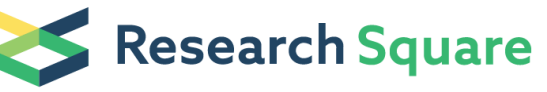 \\ Preprints are preliminary reports that have not undergone peer review. \\ They should not be considered conclusive, used to inform clinical practice, or referenced by the media as validated information.
}

\section{Porous Design of SiCNWs/SiC Nanocomposites with High Strength and Low Thermal Conductivity}

\section{Jing Ruan}

Shanghai Institute of Ceramics Chinese Academy of Sciences

Jinshan Yang ( $\nabla$ jyang@mail.sic.ac.cn )

Shanghai Institute of Ceramics Chinese Academy of Sciences https://orcid.org/0000-0002-8791-845X

Jingyi Yan

Shanghai Institute of Ceramics Chinese Academy of Sciences

Xiao You

Shanghai Institute of Ceramics Chinese Academy of Sciences

\section{Mengmeng Wang}

Shanghai Institute of Ceramics Chinese Academy of Sciences

Jianbao Hu

Shanghai Institute of Ceramics Chinese Academy of Sciences

\section{Xiangyu Zhang}

Shanghai Institute of Ceramics Chinese Academy of Sciences

\section{Yusheng Ding}

Shanghai Institute of Ceramics Chinese Academy of Sciences

\section{Shaoming Dong}

Shanghai Institute of Ceramics Chinese Academy of Sciences

\section{Research Article}

Keywords: porous nanocomposite, porosity, insulation effect

Posted Date: February 22nd, 2021

DOI: https://doi.org/10.21203/rs.3.rs-228119/v2

License: (c) (1) This work is licensed under a Creative Commons Attribution 4.0 International License.

Read Full License 


\section{Porous Design of SiCNWs/SiC Nanocomposites with High Strength and Low Thermal Conductivity}

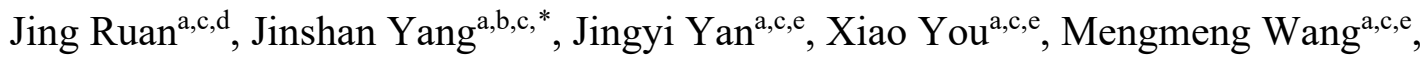

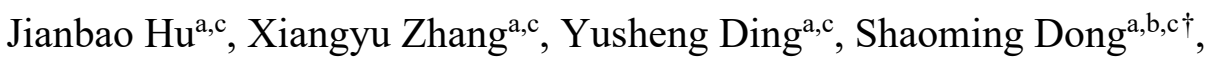

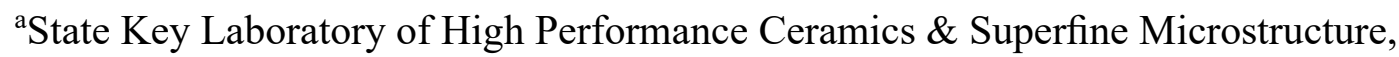
Shanghai Institute of Ceramics, Chinese Academy of Sciences, Shanghai 200050, China

${ }^{\mathrm{b} C e n t e r}$ of Materials Science and Optoelectronics Engineering, University of Chinese Academy of Sciences, Beijing 100049, China

${ }^{c}$ Structural Ceramics and Composites Engineering Research Center, Shanghai Institute of Ceramics, Chinese Academy of Sciences, Shanghai 200050, China ${ }^{\text {d} S h a n g h a i T e c h ~ U n i v e r s i t y, ~ S h a n g h a i ~ 201210, ~ C h i n a ~}$

'University of Chinese Academy of Sciences, Beijing 100039, China

Corresponding author. Tel: +86-21-69906032. Email: jyang@mail.sic.ac.cn

${ }^{\dagger}$ Corresponding author. Tel: +86-21-69906030. Email: smdong@mail.sic.ac.cn 


\begin{abstract}
Porous $\mathrm{SiC}$ composites with lightweight, high strength and low thermal conductivity design can be obtained by constructing porous silicon carbide nanowires (SiCNWs) network and controlling chemical vapor infiltration (CVI) process. The SiCNWs network with an optimized volume fraction (13.6\%) and uniform structure is prepared by mixing SiCNWs and polyvinyl alcohol (PVA) firstly. SiCNWs reinforced porous $\mathrm{SiC}$ composite $(\mathrm{SiCNW} / \mathrm{SiC})$ with a small uniform pore can be obtained by controlling the chemical deposition kinetics. The morphology of the grown $\mathrm{SiC}$ matrix, from the spherical particles to the hexagonal pyramid particles, can be influenced by the deposition parameters like temperature and reactive gas concentration. The strength of the lightweight $\mathrm{SiCNWs} / \mathrm{SiC}$ composites reach $47.8 \mathrm{MPa}$ with a porosity of $64 \%$ and thermal conductivity of $1.2 \mathrm{~W} /(\mathrm{m} \cdot \mathrm{K})$, which shows the toughening effect and insulation design with low thermal conductivity.
\end{abstract}

Keywords: porous nanocomposite; porosity; insulation effect 


\section{Introduction}

The temperature of hypersonic vehicle rises due to the violent friction between the outer wall and the air, while its internal components require a relatively low and stable temperature. To realize the lightweight and low heat transfer efficiency, porous material with the inherently half-closed pores can effectively hinder the convective heat transfer of the gas and consequently reduce the thermal conductivity [1]. Porous ceramics are relatively high-quality porous material for their lightweight, high-temperature resistance, and excellent chemical corrosion resistance performance, which can be widely used in various extreme environments [2-6]. However, the pore structure shows a negative influence on the mechanical strength of the porous ceramics $[7,8]$, in which the brittle failure can be regarded as the major obstacle in its practical application. For the improvement of brittleness, the introduction of reinforcements can be applied to toughen ceramics and may have a positive effect on the toughness of the material. SiC fibers have been used as the reinforcements of composites for its excellent performance $[9,10]$. SiCNWs possess superior physical and chemical properties compared with the traditional $\mathrm{SiC}$ fibers [11-13], and the mechanical strength of SiCNWs is an order of magnitude higher than that of $\mathrm{SiC}$ fibers [12]. SiCNWs can be considered as a new reinforcement to replace $\mathrm{SiC}$ fibers to improve the bonding strength between the pore walls for their excellent performance.

A marked risen in the elastic modulus (up to $90 \%$ ) has been reported even with the addition of a small quantity $(0.8$ vol.\%) of nanowires [14]. The yield strength of $\mathrm{SiCNWs} / \mathrm{Al}$ composites can be improved by optimizing the content of SiCNWs of 15 , 20 and 25 vol.\% [15]. As long as SiCNWs grow on carbon fiber, the interlaminar shear 
strength of SiCNWs-C/C composites can be enhanced by $32 \%$ compared with the baseline [16]. The addition of reinforcing phase can improve the strength of porous ceramic, but the strength of porous ceramic is more sensitive to pore size. Staggered one-dimensional nanowires are expected to build many nanopores, and toughen effect can be realized by the [17-19]. The low thermal conductivity of air fills the pores and the small size of pores causes less damage to mechanical strength, which make it better insulation effect and possibly existing SiCNWs-pullout is expected to improve the brittleness [20]. At present, the introduction of SiCNWs into composite materials is usually based on in-situ growth method [21-23], the purity and quality of introduced SiCNWs are difficult to be controlled. Traditional porous ceramic sintering methods are not suitable for SiCNWs application in composite, grinding and sintering will destroy nanowire structure $[24,25]$. SiCNWs are hard to be woven like SiC fibers, so it is difficult to prepare a porous SiCNWs network.

In this work, SiCNWs and PVA are mixed to form and fix SiCNWs network, and the volume fraction and pore structure parameters of the SiCNWs network is controlled by adjusting the ratio of SiCNWs and PVA. One-dimensional nanostructure of SiCNWs is used to construct a complex and porous network skeleton through controlling CVI parameters to change chemical reaction dynamics. Besides, combining morphology and pore parameters, the influence of different reaction environments on the pore structure is discussing in detail [26, 27].

\section{Experimental Procedure}

\subsection{Preparation of SiCNWs dispersion and network skeleton}


Homogenous dispersed SiCNWs solution was prepared firstly by mixing SiCNWs (Changsha Sinet Advanced Materials Co., Ltd., China) and dispersant polyvinylpyrrolidone (PVP, Hangzhou Weitong Nanometer Material Co., Ltd., China) in deionized water by sonication (Ningbo Xinzhi Biotechnology Co., Ltd., China) at $300 \mathrm{~W}$ for $100 \mathrm{~min}$. The weight ratio of SiCNWs to PVP was controlled to $6: 1$. Then, PVA was added to SiCNWs dispersion with a weight ratio of PVA : SiCNWs $=1.3: 1$. After that, the semi-dry SiCNWs/PVA mixture was poured into the mold to prepare a film with a size of $30 \times 30 \times 0.7 \mathrm{~mm}$, and the SiCNWs formed a network when the solvent was completely evaporated.

\subsection{Preparation of pyrolytic carbon interphase and $\mathrm{SiCNWs/SiC} \mathrm{composites}$}

Prior to the deposition of the SiC matrix, the SiCNWs/PVA film was put into a tube furnace for degumming and pyrolytic carbon (PyC) interphase preparation. PVA and PVP were completely removed after $60 \mathrm{~min}$ of pyrolysis at $800^{\circ} \mathrm{C}$. CVI process was applied to prepare $\mathrm{PyC}$ interphase by the pyrolysis of $\mathrm{CH}_{4}$ [28]. The $\mathrm{SiC}$ matrix was introduced into the SiCNWs network by cracking methyltrichlorosilane (MTS, $\left.\mathrm{CH}_{3} \mathrm{SiCl}_{3}\right)$ as the gaseous precursor, and hydrogen $\left(\mathrm{H}_{2}\right)$ was selected as both the carrier and dilution gas of MTS. The morphology of the deposited SiC matrix and pore size is influenced by the reaction parameters.

\subsection{Characterization}

The surface and internal morphology of the samples were characterized by scanning electron microscopy (SEM; Hitachi SU8220, Japan). The biaxial bending strength was tested by universal material testing machine (UTM, Zhejiang Zili Co., Ltd. 
Zhejiang, China), in which the samples were prepared into small flat discs with a diameter of $16 \mathrm{~mm}$. The discs were placed on three fixed spheres and formed an equilateral triangle with a side length of $7 \mathrm{~mm}$. The pore parameters were tested by mercury porosimeter (Micromeritics Instrument Co (Shanghai)., Ltd, America). The porosity of samples throughout the CVI process must be strictly analyzed, which reflects the change of the structure and pore size during the in-situ growth of the $\mathrm{SiC}$ matrix. Thermal diffusivity was tested under a laser thermal instrument (Laser thermal conductivity meter, TD-79A) from room temperature to $500{ }^{\circ} \mathrm{C}$ at a step of $50{ }^{\circ} \mathrm{C}$. Specific heat capacity was tested under high temperature specific heat tester (MHTC96, Oriental Scientific Instruments Shanghai Import and Export Co., Ltd., France).

\section{Results and Discussion}

Figure 1 shows the morphology of the SiC matrix on the SiCNWs network. In the early stage of deposition, the SiC matrix can be found wrapped in SiCNWs without interphase, as shown in Figure 1a. Differently, the grown SiC matrix aggregates into clusters and shows the state of lumpy particles in SiCNWs with PyC interphase. SiC deposits unevenly on the PyC interphase. SiC matrix deposits unevenly on the PyC interphase, which can be attributed to the weak and unstable bonding strength of $\mathrm{SiC}$ and $\mathrm{PyC}$, and consequently the bonding energy of $\mathrm{SiC}$ and $\mathrm{PyC}$ is higher than that of $\mathrm{SiC}$ and SiCNWs. When the system energy supply during MTS cracking is insufficient, the grown $\mathrm{SiC}$ tends to combine with $\mathrm{SiC}$ to reduce the dependence on system energy. The PyC interphase is not evenly covered on the SiCNWs as shown in Figure 1b. The exposed $\mathrm{SiC}$ with little covered PyC interphase becomes perfect deposition sites for 
$\mathrm{SiC}$ cracking and attaching, while the following cracked $\mathrm{SiC}$ matrix tends to grow on the fixed deposition sites and the apparent agglomeration of $\mathrm{SiC}$ can be found. Figure 1c and 1d are the surface morphology of the samples without and with PyC interphase after a long time CVI process. The sample without PyC interphase, cracked $\mathrm{SiC}$ wraps the SiCNWs and the diameter of the SiCNWs gradually increases which makes the sample denser and denser. While the sample with PyC interphase, the agglomerated SiC particles gradually grow up to contact with each other and compact the sample.
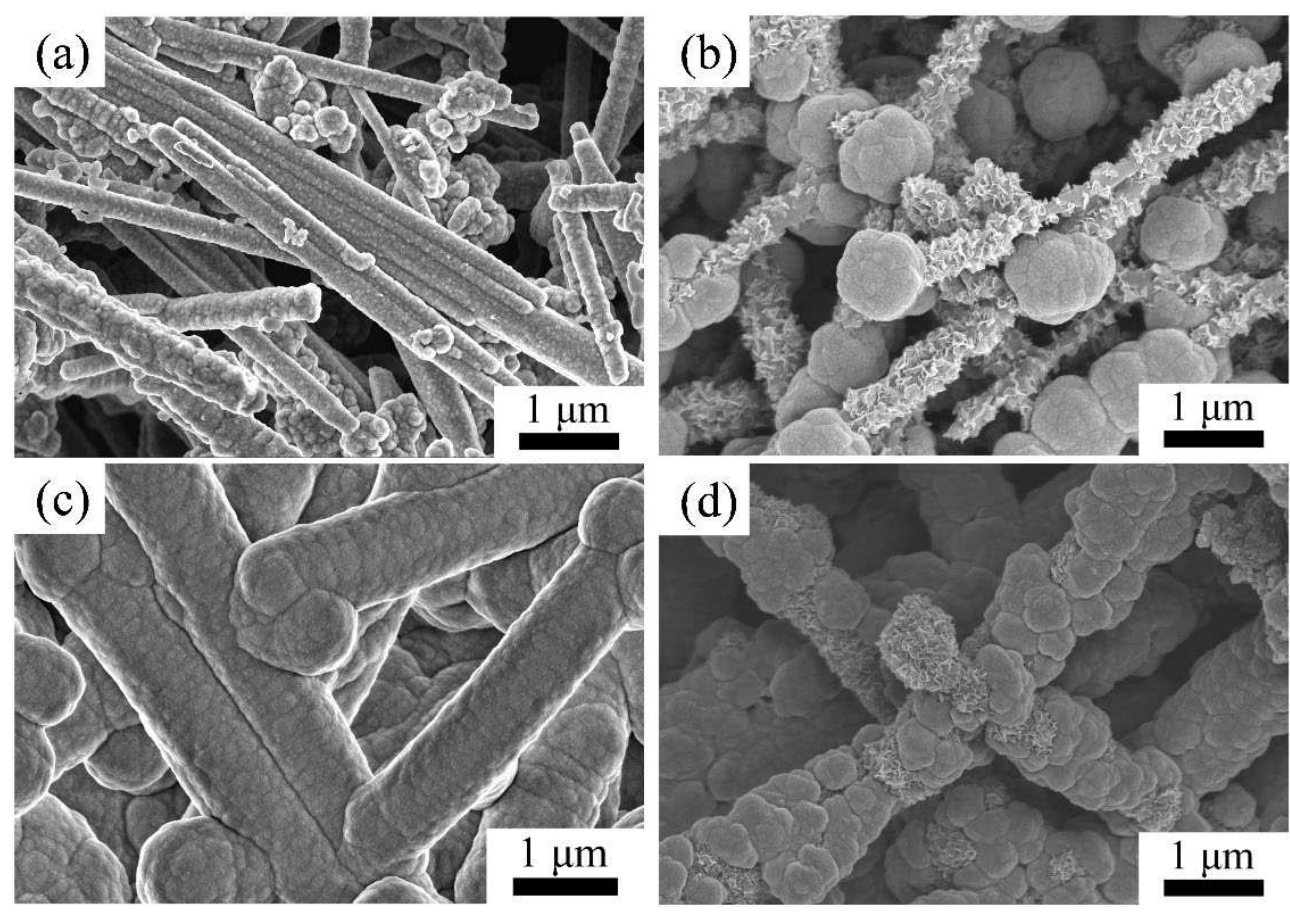

Figure 1. Surface morphology of the sample (a) without and (b) with PyC interphase after short time CVI process respectively. Surface morphology of the sample (c) without and (d) with PyC interphase after long time CVI process respectively. The deposition temperature shows a significant effect on the growth morphology of the $\mathrm{SiC}$ matrix. As shown in Figure 2, the $\mathrm{SiC}$ matrix tends to preferentially grow into spherical particles when the temperature is lower than $950^{\circ} \mathrm{C}$, while transforms into a hexagonal pyramidal when the temperature rises to $1030^{\circ} \mathrm{C}$. Subsequently, the 
hexagonal pyramidal $\mathrm{SiC}$ matrix is still dominated when the temperature rises to $1100{ }^{\circ} \mathrm{C}$, but its particle size is significantly larger than that of the matrix at $1030{ }^{\circ} \mathrm{C}$. Generally, reaction temperature and pressure are all important parameters that affect the growth morphology, which is associated with the reaction activity and energy. The pyrolysis of the precursor and the in-situ grown of the $\mathrm{SiC}$ matrix are processes of nucleation and re-growth, and the volume energy and surface energy are major factors to be considered. For the growth of the $\mathrm{SiC}$ matrix, the energy required by the system as follows:

$\nabla G=\left(\frac{4 \pi r^{3}}{3}\right) \nabla G_{V}+4 \pi r^{2} \sigma$

Hemispherical particles: $\frac{d_{v}}{d_{s}}=\frac{\mathrm{r}}{2}$

Cone particles: $\frac{d_{v_{1}}}{d_{s_{1}}}=\frac{\mathrm{r}}{2} \sin \theta$

where $\nabla G$ is the total energy required for $\mathrm{SiC}$ deposition, $\nabla G_{V}$ is the volume energy of $\mathrm{SiC}, \sigma$ is the surface energy of SiC. $v$ and $S$ are the volume and surface of the grown $\mathrm{SiC}$, respectively. In previous research, there are three growth morphologies of the grown $\mathrm{SiC}$ matrix obtained by the CVI process, including spherical, conical, and hexagonal cone shape [29]. Under the same growth conditions, the growth of the hexagonal cone shape requires the highest surface energy, while the growth of spherical shape requires the lowest surface energy [30]. Therefore, at low temperatures, the SiC matrix tends to preferentially grow into a spherical shape to reduce energy requirements, which can be attributed to the insufficient system energy supply. When the temperature rises, which means enough system supply, the spherical $\mathrm{SiC}$ matrix deposition can transform into hexagonal cone deposition. Moreover, the $\mathrm{SiC}$ matrix can also be 
deposited on the angle between the surfaces of two crystal grains to reduce energy requirements.
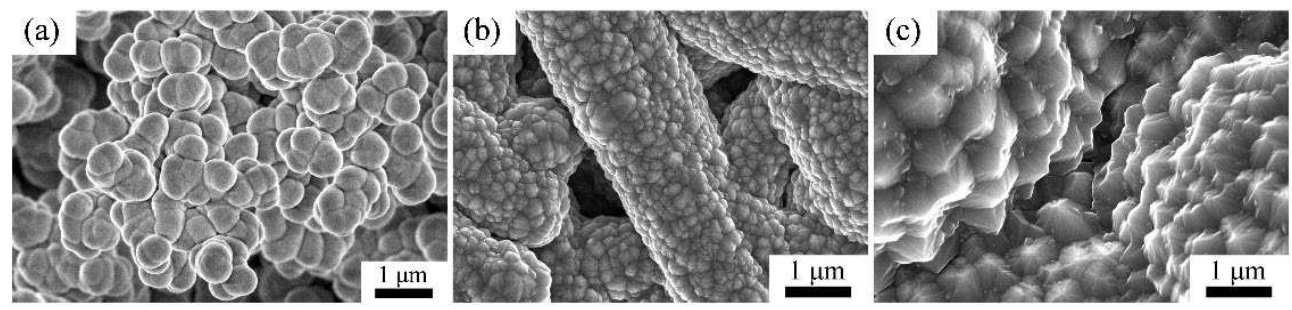

Figure 2. The growth morphology of $\mathrm{SiC}$ matrix at different temperatures. (a)

$$
950{ }^{\circ} \mathrm{C}, \text { (b) } 1030{ }^{\circ} \mathrm{C}, \text { (c) } 1100^{\circ} \mathrm{C} \text {. }
$$

The external surface and fracture surface morphology of the prepared SiCNWs/SiC composites with various deposition temperatures are characterized by scanning electron microscopy (SEM) in Figure 3. The surface of the samples with $1030{ }^{\circ} \mathrm{C}$ and $1100{ }^{\circ} \mathrm{C}$ shows dense and little open pore, indicating that the continuous CVI process makes no effort for internal pore filling. As shown in Figure 3d, the more convex $\mathrm{SiC}$ spheres can be attributed to the increase in temperature that accelerates the pyrolysis of the precursor, and consequently the $\mathrm{SiC}$ matrix grows directly on the surface of the sample. The cross-section view in Figure $3 \mathrm{~b}$ and $3 \mathrm{e}$ demonstrates that the sample at $1030{ }^{\circ} \mathrm{C}$ is denser than that of the $1100{ }^{\circ} \mathrm{C}$ sample, in which the layer thickness of grown $\mathrm{SiC}$ matrix is $270 \mathrm{~nm}$ and $130 \mathrm{~nm}$, respectively. Therefore, the increase in temperature will increase the surface density and decrease the internal density, which can be explained by reaction kinetics. The movement of the precursor MTS in the horizontal direction is mainly determined by pumping force, whether it entered the internal pore of the SiCNWs film is influenced by molecular thermal movement. So it caters to Arrhenius formula [31]: 
$\frac{t_{2}}{t_{1}}=\frac{K_{1}}{K_{2}}$

$\boldsymbol{K}=\mathrm{A} e^{\frac{-E_{a}}{R T}}$

$\mathcal{V}=\sqrt{\frac{8 \kappa \mathrm{T}}{\pi \mathrm{m}}}$

$\frac{L_{2}}{L_{1}}=\frac{V_{2} t_{2}}{V_{1} t_{1}}$

in which $\mathcal{V}_{1}$ and $\mathcal{V}_{2}$ are the average molecular thermal motion rate, $\boldsymbol{K}$ is the rate constant that represents the probability of pyrolysis per unit time, $\kappa$ is Boltzmann constant, $E_{a}$ is the reaction activation energy, $\mathrm{T}$ is the temperature of the tube furnace, $\mathrm{A}$ is a constant, $\mathrm{m}$ is the molecular weight of MTS, $t_{2}$ and $t_{1}$ are the average thermal motion time of MTS before pyrolysis, $\mathrm{L}$ is the sum of thermal motion trajectory. $\mathcal{V}_{1}$ approximately equal $\mathcal{V}_{2}$, so $\frac{L_{2}}{L_{1}} e^{\frac{-E_{a}}{R}}\left(\frac{1}{T_{1}}-\frac{1}{T_{2}}\right)$. Lowering the temperature means more time left for the process that MTS fully decomposed into $\mathrm{SiC}$, which is considered to that reducing reaction temperature can increase the pyrolysis time of MTS, thus extending the migration distance of MTS and increasing the chance for MTS to enter the internal channel. However, excessively lowering the temperature may change the growth state of the $\mathrm{SiC}$ matrix, or generate easily oxidized free silicon, which will eventually affect the performance of the composites [32-35].
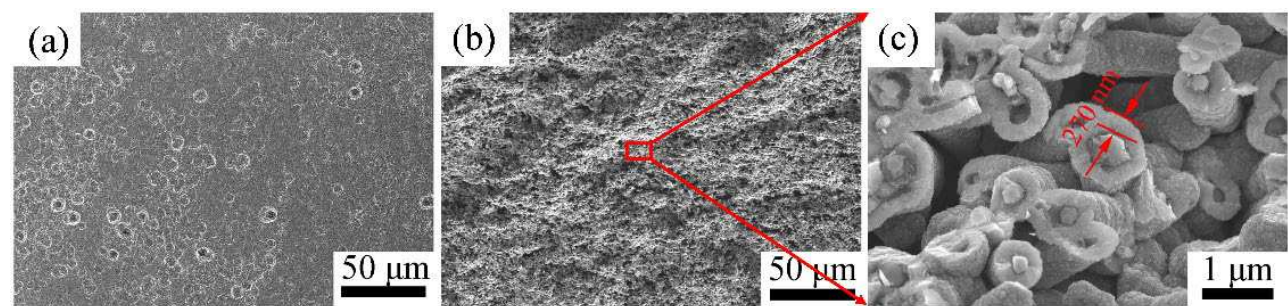

(d)

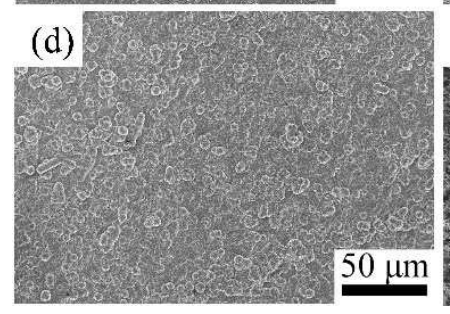

(e)
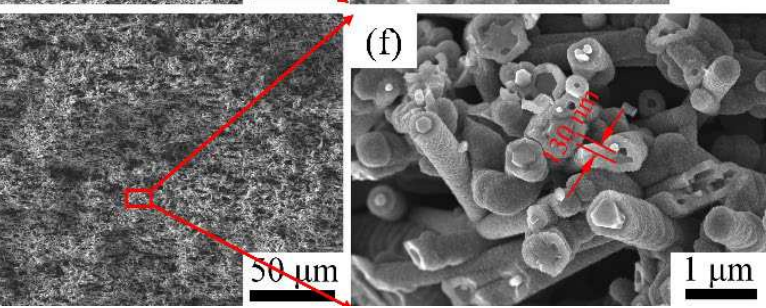
Figure 3. SEM images of the prepared $\mathrm{SiCNW} / \mathrm{SiC}$ composites. (a) External surface view of the sample under 8 hour CVI process at $1030^{\circ} \mathrm{C}$. (b) Fracture surface view and (c) corresponding enlarged region of the sample under 8 hours CVI process at

$1030{ }^{\circ} \mathrm{C}$. (d) External surface view of the sample under 8 hours CVI process at $1100^{\circ} \mathrm{C}$. (e) Fracture surface view and (f) corresponding enlarged region of the sample under 8 hours CVI process at $1100{ }^{\circ} \mathrm{C}$.

The distribution of the pore size of the as-prepared $\mathrm{SiCNW} / \mathrm{SiC}$ composites with different porosity is shown in Figure 4a. The slope of the curve represents the proportion of pores of a certain size and a large slope corresponds to more pores of this size. The in-situ deposition SiC wraps SiCNWs and the diameter of SiCNWs increases. $\mathrm{SiC}$ effectively fills the pores and the pore size and porosity of the composite decreases. With the growth of the $\mathrm{SiC}$ matrix, the porosity decreases to $48 \%$, and the proportion of small pores decrease rapidly, which indicates that the small pores on the surface are gradually blocked. Figure $4 \mathrm{~b}$ shows that the change of average pore diameter (APd) and median pore diameter (MPd) with decreasing porosity. APd value rises slightly when the porosity decrease from $48.1 \%$ to $38.9 \%$, which can be attributed to the small pores gradually being blocked. In the initial state of the deposition of the $\mathrm{SiC}$ matrix, precursor MTS can flow pass through the small channels, while the large pores are difficult to deposit the matrix. Due to the adsorption effect between MTS and pore walls, MTS molecules prefer to attach to pore walls and flow through large pores, resulting in accelerat the blockage of small pores and the MPd value increases rapidly. As the porosity continues to decrease, the large pores are gradually filled into small pores, 
which continues to reduce the MPd value. As shown in Figure 4c, the prepared $\mathrm{SiCNW} / \mathrm{SiC}$ composites with a porosity of $48.1 \%$ show clear small pores on the surface.

(a)

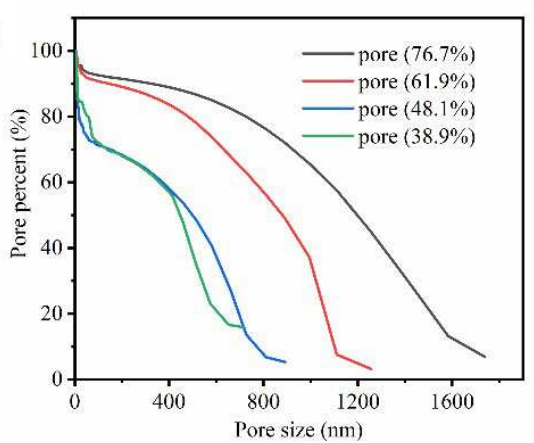

(b)

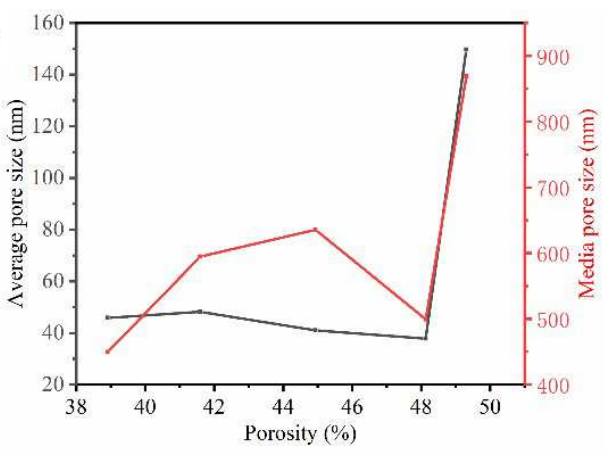

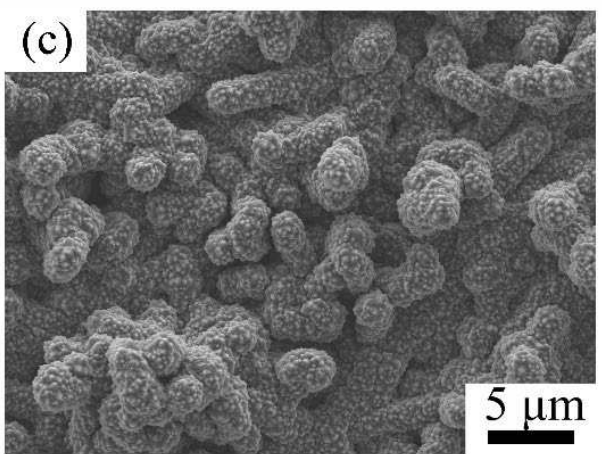

Figure 4. (a) Pore size distribution of samples with different porosity. (b) The changes of average pore diameter and median pore diameter with different porosity. (c) The surface morphology of the sample with a porosity of $48.1 \%$.

The porous structure shows a significant impact on the strength and thermal conductivity of the as-prepared $\mathrm{SiCNWs} / \mathrm{SiC}$ composites. As shown in Figure 5a, the biaxial bending strength increases with the decrease of the porosity, the in-situ grown $\mathrm{SiC}$ wraps the SiCNWs, which results in the diameter of the SiCNWs increasing and gradually making the network form a whole, loading and lattice thermal shock can effectively transfer between SiCNWs. The deposition SiC matrix effectively enhances the connection and heat conduction between SiCNWs, and the enhancement effect increases as the amount of in-situ grown $\mathrm{SiC}$ increases. More interestingly, the sample 
with the porosity of $64 \%$ shows almost the same thermal conductivity of $1.2 \mathrm{~W} / \mathrm{m} \cdot \mathrm{K}$ as the sample with the porosity of $75 \%$, which demonstrates that the thermal conductivity is not affected by porosity. The distribution map of the pore size of the sample with the porosity of $64 \%$ and $75 \%$ are shown in Figure $5 \mathrm{~b}$ and $5 \mathrm{c}$. The sample with $64 \%$ porosity shows a more uniform pore size distribution, in which the pores are mostly distributed in small size. The total surface area of the pores of the sample with $64 \%$ porosity is 59 $\mathrm{m}^{2} / \mathrm{g}$, which is higher than that $52 \mathrm{~m}^{2} / \mathrm{g}$ of $75 \%$ sample. The porosity decreases but the surface area increases, which is attributed to that the sample with $75 \%$ sample shows a good connection between SiCNWs, the continued in-situ deposition SiC makes little effect to construct new faster heat conduction channels. Besides the large pores are divided into more small pores, the newly generated section makes little effect on heat transfer. While the transition from large pores to small pores increases the strength of the $\mathrm{SiCNW} / \mathrm{SiC}$ composites from 33.6 MPa to 47.8 MPa.

(a)

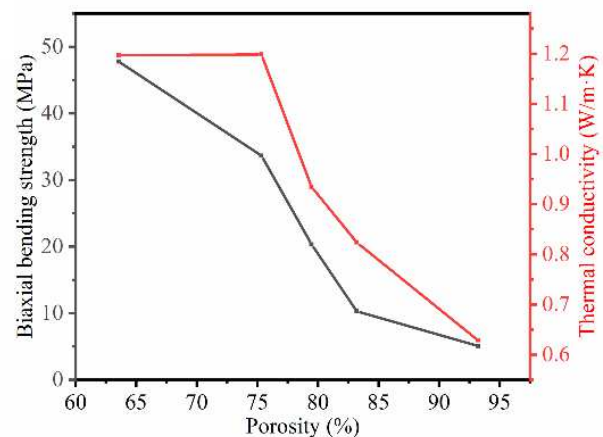

(b)

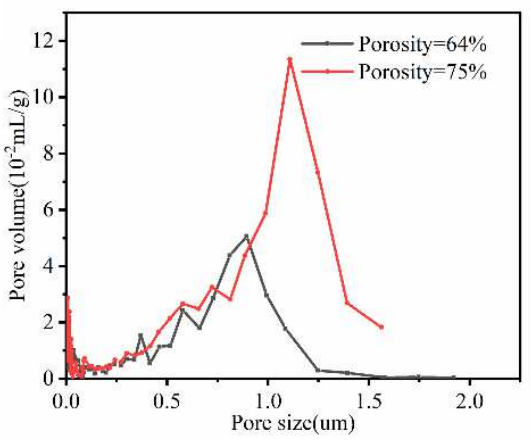

(c)

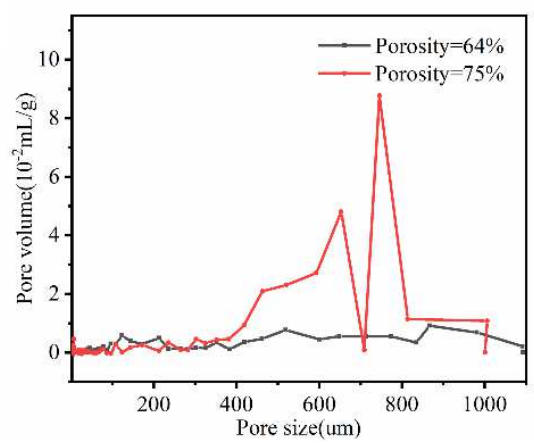

Figure 5. (a) Changes in strength and thermal conductivity of porous SiCNWs/SiC 
nanocomposite. The detailed pore distribution of the sample with $64 \%$ and $75 \%$ porosity: (b) The pore size from 0 to $2.0 \mathrm{um}$. (c) The pore size from 2.0 to $1200 \mathrm{um}$. 


\section{Conclusion}

The porous SiCNWs network framework with a volume fraction of $13.6 \%$ was prepared by mixing SiCNWs and PVA colloids. Through controlling CVI parameters to change the chemical reaction dynamics, three different in-situ grown $\mathrm{SiC}$ micro morphologies were obtained. Under different chemical reaction kinetics, the density and pore structure parameters of the porous $\mathrm{SiCNWs} / \mathrm{SiC}$ composite are also very different. The $\mathrm{SiCNWs} / \mathrm{SiC}$ composite with a porosity of $64 \%$ possesses thermal conductivity of $1.2 \mathrm{~W} / \mathrm{m} \cdot \mathrm{K}$ and biaxial bending strength of $47.8 \mathrm{MPa}$. 


\section{Acknowledgement}

This work was supported by National Natural Science Foundation of China (No.

51772310), Chinese Academy of Sciences Key Research Program of Frontier Sciences (QYZDY-SSWJSC031), and Innovation Academy for Light-duty Gas Turbine, Chinese Academy of Sciences (CXYJJ20-MS-02). 


\section{Reference}

[1] Li S, Zeng X, Chen H, et al. Porous hexagonal boron nitride nanosheets from gC3N4 templates with a high specific surface area for $\mathrm{CO}_{2}$ adsorption. Ceram Int 2020, 46 (17): 27627-27633.

[2] Saravanan S, Chidambaram RK, Geo VE. An experimental study to analyze influence of porous media combustor on performance and emission characteristics of a DI diesel engine. Fuel 2020, 280: 118645.

[3] Bicy K, Kalarikkal N, Stephen A M, et al. Facile fabrication of microporous polypropylene membrane separator for lithium-ion batteries. Mater Chem Phys 2020, 255: 123473.

[4] Pan B, Chen J, Zhang F, et al. Porous $\mathrm{TiO}_{2}$ aerogel-modified SiC ceramic membrane supported MnOx catalyst for simultaneous removal of NO and dust. J Membr Sci 2020, 611: 118366.

[5] Song X, Jian BJin J. Preparation of porous ceramic membrane for gas-solid separation. Ceram Int 2018, 44 (16): 20361-20366.

[6] Wang Z, Pan Z. Preparation of hierarchical structured nano-sized/porous poly(lactic acid) composite fibrous membranes for air filtration. Appl Surf 2015, 356: 11681179.

[7] Liu X, Martin C L, Bouvard D, et al. Strength of Highly Porous Ceramic Electrodes. J Am Ceram Soc 2011, 94 (10): 3500-3508.

[8] Huo W, Zhang X, Chen Y, et al. Mechanical strength of highly porous ceramic foams with thin and lamellate cell wall from particle-stabilized foams. Ceram Int 2018, 44 
(5): 5780-5784.

[9] Saucedo-Mora L, Lowe T, Zhao S, et al. In situ observation of mechanical damage within a SiC-SiC ceramic matrix composite. J Nucl Mater 2016, 481: 13-23.

[10] Song C, Liu X, Ye F, et al. Mechanical and dielectric properties of SiCf/BN/SiBCN composites via different synthesis technologies. J Eur Ceram Soc 2019, 39 (14): 4417-4423.

[11] Wang H, Zhou X, Yu J, et al. Fabrication of $\mathrm{SiCf} / \mathrm{SiC}$ composites by chemical vapor infiltration and vapor silicon infiltration. Mater Lett 2010, 64 (15): 16911693.

[12] Wong EW, Sheehan PE, Lieber CM. Nanobeam Mechanics: Elasticity, Strength, and Toughness of Nanorods and Nanotubes. Science 1997, 277 (5334): 1971-1975.

[13] Zhang Y, Han X, Zheng K, et al. Direct Observation of Super-Plasticity of BetaSiC Nanowires at Low Temperature. Adv Funct 2007, 17 (17): 3435-3440.

[14] Vivekchand SRC, Ramamurty U, Rao CNR. Mechanical properties of inorganic nanowire reinforced polymer-matrix composites. Nanotechnology 2006, 17 (11): S344-S350.

[15] Xin L, Yang W, Zhao Q, et al. Strengthening behavior in SiC nanowires reinforced pure Al composite. $J$ Alloys Compd 2017, 695: 2406-2412.

[16] Qingliang S, Hejun L, Lu L, et al. SiC nanowire reinforced carbon/carbon composites with improved interlaminar strength. Mater Sci Eng:A 2016, 651: 583589.

[17] Quan-Li J I A, Wen-Hao W U, Jun Z, et al. Carbon Nanotube Modified Sepiolite 
Porous Ceramics for High-efficient Oil/Water Separation. Inorg Mater 2019, 35(6).

[18] Zhang KJ, Yadav A, Kim KH, et al. Thermal and electrical transport in ultralow density single-walled carbon nanotube networks. Adv Mater 2013, 25 (21): 29262931.

[19] Zhao X, Huang C, Liu Q, et al. Thermal conductivity model for nanofiber networks. J Appl Phys 2018, 123 (8): 085-103.

[20] Ma R, Cheng X, Ye W. SiC fiber and yttria-stabilized zirconia composite thick thermal barrier coatings fabricated by plasma spray. Appl Surf 2015, 357: 407-412.

[21] Zhuang L, Fu Q-G, Liu T-Y, et al. In-situ PIP-SiC NWs-toughened SiC-CrSi2$\mathrm{Cr}_{3} \mathrm{C}_{2}-\mathrm{MoSi}_{2}-\mathrm{Mo}_{2} \mathrm{C}$ coating for oxidation protection of carbon/carbon composites. J Alloys Compd 2016, 675: 348-354.

[22] Chu Y, Li H, Fu Q, et al. Toughening by SiC Nanowires in a Dense SiC-Si Ceramic Coating for Oxidation Protection of C/C Composites. J Am Ceram Soc 2012, 95 (11): $3691-3697$.

[23] Wang D, Xue C, Bai H, et al. Silicon carbide nanowires grown on graphene sheets. Ceram Int 2015, 41 (4): 5473-5477.

[24] Nguyen VH, Delbari SA, Ahmadi Z, et al. Electron microscopy characterization of porous $\mathrm{ZrB}_{2}-\mathrm{SiC}-\mathrm{AlN}$ composites prepared by pressureless sintering. Ceram Int 2020, 46 (16): 25415-25423.

[25] Li X, Yao D, Zuo K, et al. Microstructure and permeability of porous YSZ ceramics fabricated by freeze casting of oil-in-water suspension. J Eur Ceram Soc 2020, 40 (15): 5845-5851. 
[26] Fitzer E, Hegen D. Chemical vapor-deposition of silicon-carbide and siliconnitride - chemistrys contribution to modern silicon ceramics. Angew Chem Int Ed 1979, 18 (4): 295-304.

[27] Naslain R, Rossignol JY, Hagenmuller P, et al. Synthesis and properties of new composite-materials for high-temperature applications based on carbon-fibers and C-SiC or C-TiC hybrid matrices. Revue De Chimie Minerale 1981, 18 (5): 544564.

[28] Ruan J, Yang J, Dong S, et al. Interfacial optimization of SiC nanocomposites reinforced by SiC nanowires with high volume fraction. J Am Ceram Soc 2019, 102 (9): 5033-5037.

[29] Zhu Y, Zhang W, Yan LS, et al. Interface between Multi-layered CVD SiC Coating and Its Graphite Substrate, Equipment Environmental Engineering 2019, 16 (10), 59-63.

[30] Chin J, Gantzel PK, Hudson RG. The Structure of Chemical Vapor Deposition Sillicon Carbide, Thin Solid Films 1977, 40: 57-72.

[31] Maslov MM, Openov LA. Podlivaev AI, On the vineyard formula for the preexponential factor in the Arrhenius law, Physics of the Solid State 2014, 56 (6): $1239-1244$.

[32] Tiegs TN. Fission Product Pd-SiC Interaction in Irradiated Coated-Particle Fuels, Nucl Technol 2017, 57(3): 389-398.

[33] Kingon AI, Lutz LJ, Liaw P, et al. Thermodynamic Calculations for the Chemical Vapor Deposition of Silicon Carbide, J Am Ceram Soc 1983, 66(8): 558-566. 
[34] Minato K, Fukuda K. Structure of chemically vapour deposited silicon carbide for coated fuel particles, J Mater Sci 1988, 23: 699-706.

[35] Choi BJ. Chemicalvapour deposition of silicon carbide by pyrolysis of methylchlorosilanes, J Mater Sci 1997, 16: 33-36. 


\section{Figures}
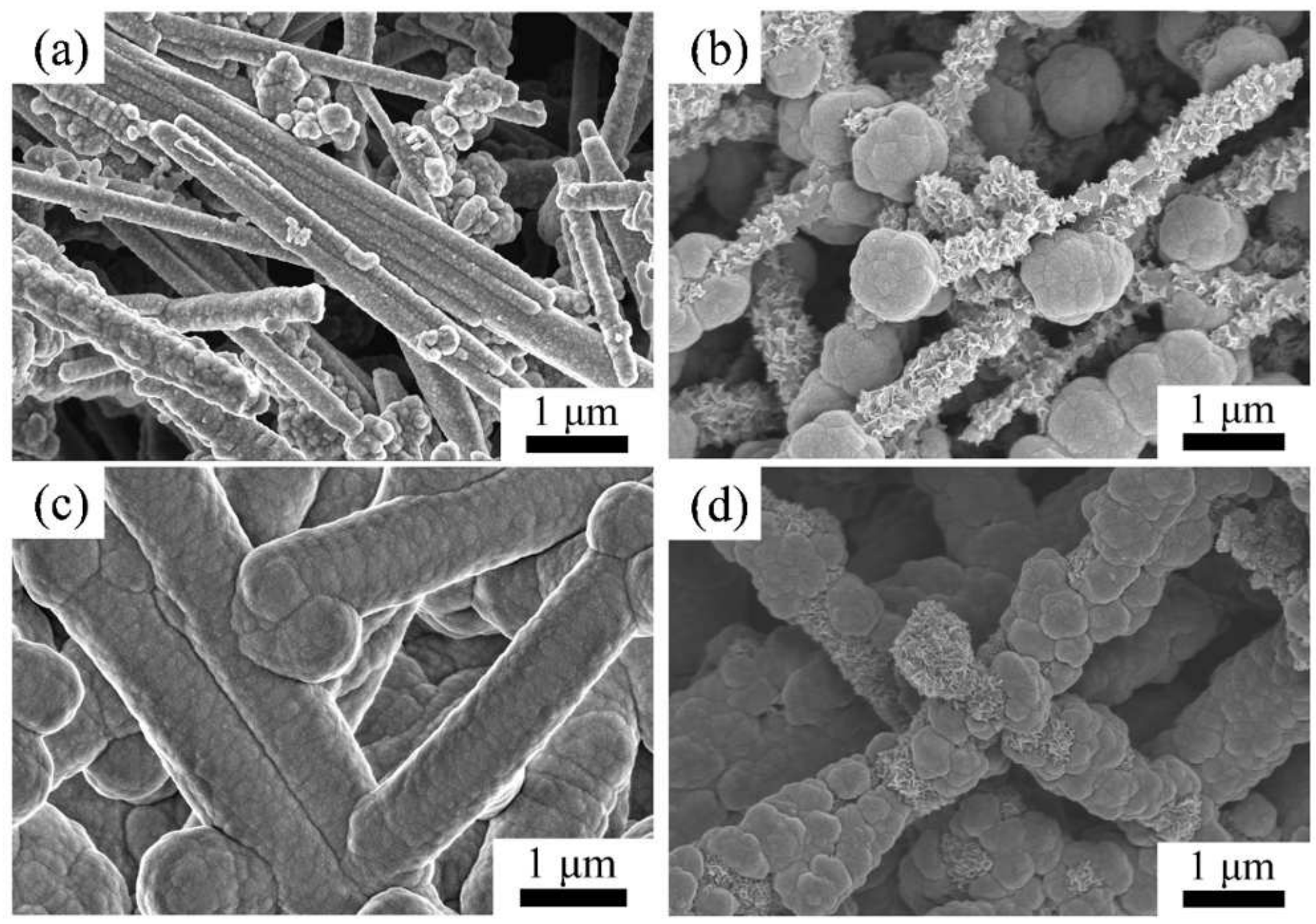

Figure 1

Surface morphology of the sample (a) without and (b) with PyC interphase after short time CVI process respectively. Surface morphology of the sample (c) without and (d) with PyC interphase after long time CVI process respectively.
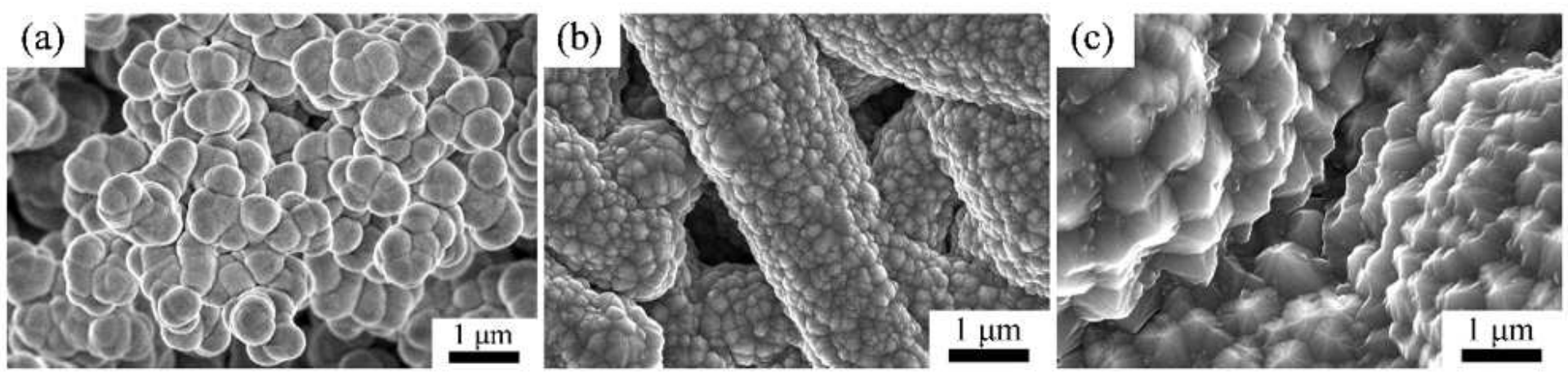

Figure 2 
The growth morphology of SiC matrix at different temperatures. (a) $950^{\circ} \mathrm{C}$, (b) $1030^{\circ} \mathrm{C}$, (c) $1100^{\circ} \mathrm{C}$.
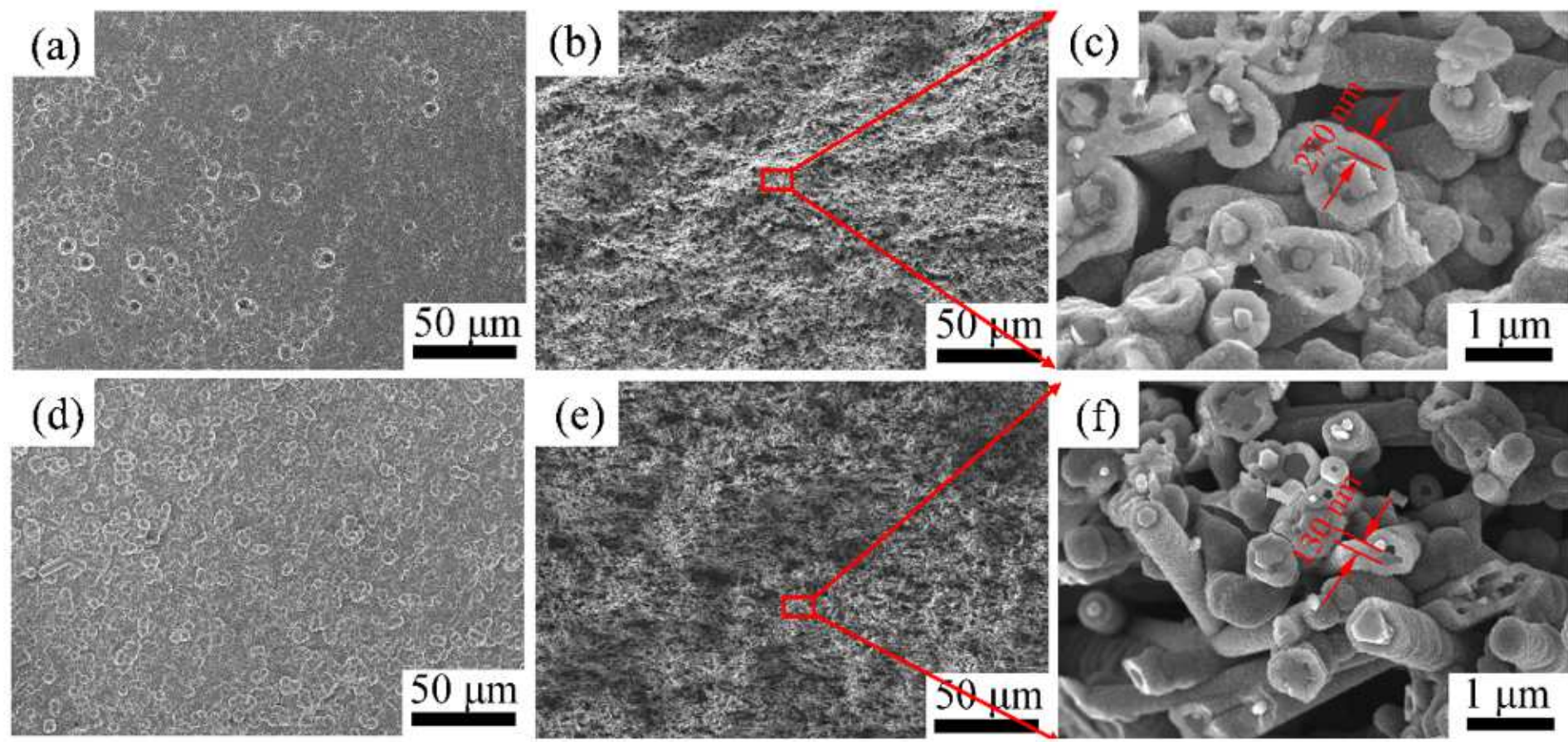

\section{Figure 3}

SEM images of the prepared SiCNWs/SiC composites. (a) External surface view of the sample under 8 hour CVI process at $1030^{\circ} \mathrm{C}$. (b) Fracture surface view and (c) corresponding enlarged region of the sample under 8 hours CVI process at $1030^{\circ} \mathrm{C}$. (d) External surface view of the sample under 8 hours CVI process at $1100^{\circ} \mathrm{C}$. (e) Fracture surface view and (f) corresponding enlarged region of the sample under 8 hours CVI process at $1100^{\circ} \mathrm{C}$. 
(a)

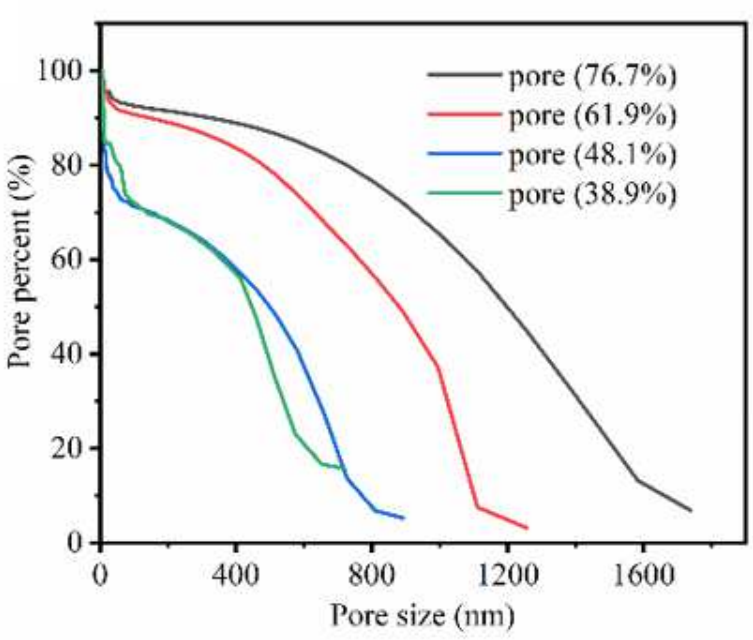

(b)

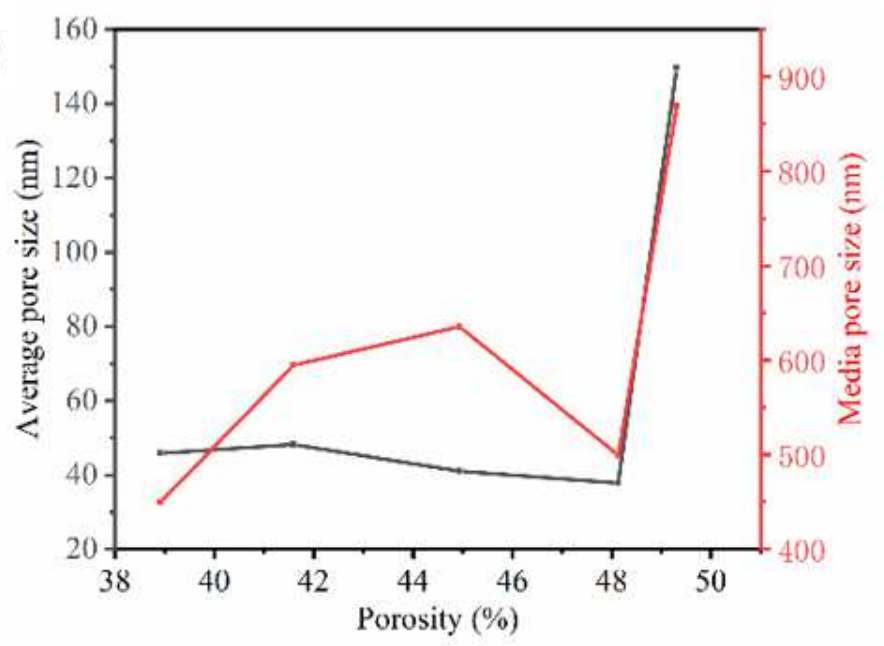

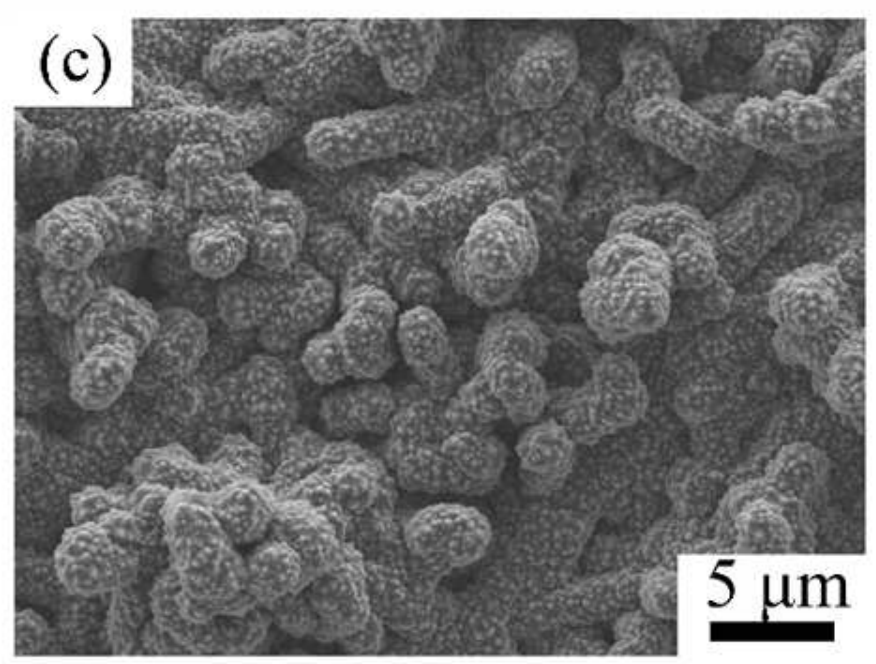

\section{Figure 4}

(a) Pore size distribution of samples with different porosity. (b) The changes of average pore diameter and median pore diameter with different porosity. (c) The surface morphology of the sample with a porosity of $48.1 \%$. 
(a)

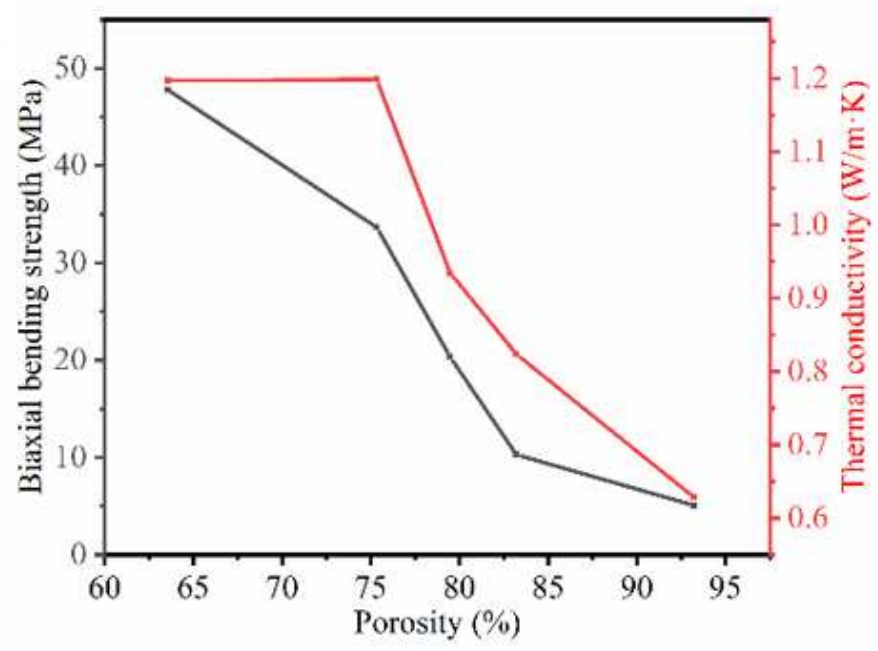

(b)

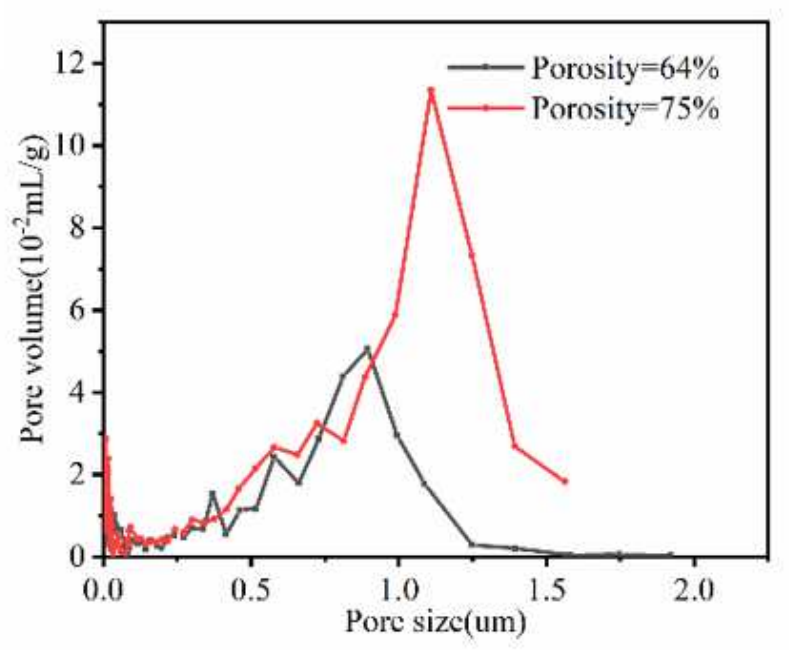

(c)

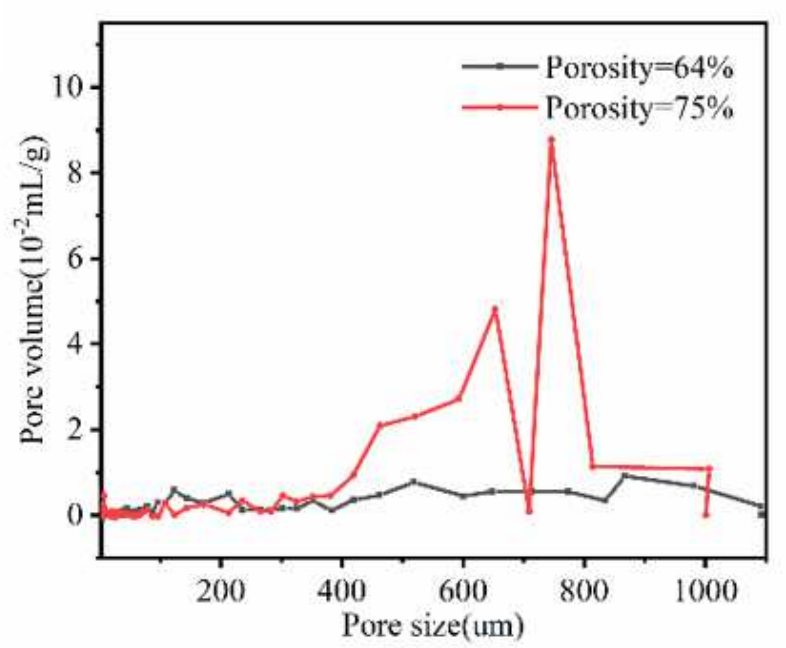

Figure 5

(a) Changes in strength and thermal conductivity of porous SiCNWs/SiC nanocomposite. The detailed pore distribution of the sample with $64 \%$ and $75 \%$ porosity: (b) The pore size from 0 to $2.0 \mathrm{um}$. (c) The pore size from 2.0 to 1200 um. 